Research Article

\title{
Effects of L1-ORF2 fragments on green fluorescent protein gene expression
}

Xiu-Fang Wang, Xia Jin, Xiaoyan Wang, Jing Liu, Jingjing Feng, QinQing Yang, Wenli Mu, Xiaojuan Shi and Zhanjun Lu

Hebei Key Lab of Laboratory Animal, Department of Genetics, Hebei Medical University, Shijiazhuang, Hebei Province, China.

\begin{abstract}
The retrotransposon known as long interspersed nuclear element-1 (L1) is 6 kb long, although most L1s in mammalian and other eukaryotic cells are truncated. L1 contains two open reading frames, ORF1 and ORF2, that code for an RNA-binding protein and a protein with endonuclease and reverse transcriptase activities, respectively. In this work, we examined the effects of full length L1-ORF2 and ORF2 fragments on green fluorescent protein gene (GFP) expression when inserted into the pEGFP-C1 vector downstream of GFP. All of the ORF2 fragments in sense orientation inhibited GFP expression more than when in antisense orientation, which suggests that small ORF2 fragments contribute to the distinct inhibitory effects of this ORF on gene expression. These results provide the first evidence that different 280-bp fragments have distinct effects on the termination of gene transcription, and that when inserted in the antisense direction, fragment 280-9 (the 3' end fragment of ORF2) induces premature termination of transcription that is consistent with the effect of ORF2.
\end{abstract}

Key words: gene expression, green fluorescent protein gene, L1-ORF2, transcription termination, orientation.

Received: February 26, 2009; Accepted: May 15, 2009.

\section{Introduction}

Type 1 long interspersed nuclear elements (L1s) are the most abundant autonomous retrotransposons in mammals, and comprise $17 \%$ of the human genome (Kazazian and Moran, 1998; Smit et al., 1999; Lander et al., 2001; Abrusán et al., 2008). Intact L1 is $\sim 6 \mathrm{~kb}$ long, has an internal promoter for RNA polymerase II and encodes two polypeptides essential for retrotransposition (Swergold, 1990; Moran et al., 1996; Athanikar et al., 2004). The product of ORF1 is an RNA-binding protein, whereas ORF2 encodes a protein with endonuclease and reverse transcriptase activities (Feng et al., 1996; Martin and Bushman, 2001; Cost et al., 2002; Weichenrieder et al., 2004; Martin et al., 2005). L1 elements replicate via target-site primed reverse transcription, which combines chromosomal insertion with reverse transcription (Cost et al., 2002).

Although elements of L1 can occur almost anywhere in the mammalian genome, their abundance varies among genomic regions. In general, these elements are much more abundant in genomic regions that are AT-rich, have a lowrecombination frequency and are gene-poor (Pavlicek et al., 2001; Yang et al., 2004; Hackenberg et al., 2005; Belancio et al., 2006; Graham and Boissinot, 2006). In human genes, L1s preferentially have an antisense orientation

Send correspondence to: Zhanjun Lu. Hebei Key Lab of Laboratory Animal, Department of Genetics, Hebei Medical University, 361 Zhongshan East Road, Shijiazhuang, Hebei Province, 050017 China. E-mail: Islab@hebmu.edu.cn. and most copies are truncated (Sassaman et al., 1997; Boissinot et al., 2000; Sheen et al., 2000; Lander et al., 2001), rearranged (Skowronski and Singer, 1986) or both. These findings imply that the length and orientation of L1s have different effects on genes. It would therefore seem highly important to study the effects of L1 fragments and their orientations on gene expression.

L1s can cause the retrotransposition of Alu (Dewannieux et al., 2003) and mediate the cell growth and differentiation associated with this event (Ergün et al., 2004; Sciamanna et al., 2005). Han et al. (2004) reported that L1.2-ORF2 in the sense orientation inhibited GFP expression much more than when in antisense orientation. By using appropriate deletions these authors also showed that the inhibition of gene expression varied with the length of the L1.2-ORF2 fragment.

In this study, we used L1PA3, a subfamily of L1s that shares $96 \%$ similarity with L1.2-ORF2, to examine whether L1PA3-ORF2 has the same effect on gene expression as L1.2-ORF2. Seven 280-bp fragments obtained by the polymerase chain reaction (PCR) from different regions of L1PA3-ORF2 (ORF2) were fused in tandem to GFP in order to examine their effect on gene expression.

\section{Materials and Methods}

\section{Plasmid construction}

Tandem repeat plasmids (Table 1 ) were constructed as previously described (Okano et al., 2008) and were iden- 
tified by digestion with the restriction enzyme pair HindIII/ Nhe I and DNA sequencing (Generay Co. Shanghai, China). The primers used for PCR are shown in Table 2.

\section{Cell culture and cell transfection}

HeLa cells were routinely cultured in Dulbecco's modified Eagle's medium (DMEM) with 10\% fetal calf serum (FCS). Aliquots containing $1.8 \times 10^{5}$ cells $/ \mathrm{mL}$ were plated in 12-well plates and then cultured at $37{ }^{\circ} \mathrm{C}$ in $5 \%$ $\mathrm{CO}_{2}$ for $24 \mathrm{~h}$. At approximately 50\%-70\% confluence, the cells were transfected with $1.5 \mu \mathrm{g}$ of plasmid DNA and $3 \mu \mathrm{L}$ of liposomes (Lipofectamine 2000; Invitrogen, Grand Island, NY) in order to observe fluorescent cells and to generate RNA for subsequent experiments.

\section{Assessment of GFP reporter protein}

The expression of GFP reporter protein was assessed by fluorescence microscopy of transfected HeLa cells.

\section{Northern blotting}

The GFP probe was labeled with $\left[{ }^{32} \mathrm{P}\right]$-deoxycytidine triphosphate (dCTP) via PCR using the primers shown in Table 2. Total RNA was extracted from plasmid-transfected $\mathrm{HeLa}$ cells with Trizol reagent (Invitrogen, Inc.) $36 \mathrm{~h}$ after transfection. The RNA was electrophoresed in a $1.2 \%$ agarose gel denatured with $3 \%$ formaldehyde followed by transferring to nylon membranes in 20x salt-sodium citrate (SSC) for $24 \mathrm{~h}$. RNA was cross-linked to the membranes by exposure to UV light and the membranes then incubated with the $G F P$ probe at $42{ }^{\circ} \mathrm{C}$ followed by autoradiography. The membranes were subsequently stripped by washing twice at $80{ }^{\circ} \mathrm{C}$ for $1 \mathrm{~h}$ with 50 $\mathrm{mM}$ Tris, $\mathrm{pH} 7.4$, containing $50 \%$ formamide and $5 \%$ sodium dodecylsulfate (SDS), and then hybridized with a $\left[{ }^{32} \mathrm{P}\right]$-labeled probe for neo mRNA (the cassette for neomycin resistance). This probe was prepared by PCR amplification with the primers shown in Table 2.

\section{Results}

\section{Effects of ORF2 in sense and antisense orientations on GFP expression}

ORF2 (3825 bp) or the lac $Z$ sequence was inserted downstream of GFP in the pEGFP-C1 vector. The insertion of ORF2 in sense or antisense orientation significantly decreased GFP RNA (Figure 1) and protein (data not shown) expression. To demonstrate this decrease, we used Xho I IPst I or Apa I restriction enzymes to construct plasmids of pORF2, pORF2as, pORF2Apa and pORF2asApa (see Table 1). When ORF2 was inserted in the sense orientation (pORF2), GFP RNA production was only $3.6 \%$ of that seen with ORF2 in the antisense orientation (pORF2as) (Figure 1, lane $1 v s$. lane 2), and when ORF2Apa was inserted in the sense orientation (pORF2Apa) GFP RNA production was $4.2 \%$ of that seen with ORF2Apa in the antisense orientation (pORF2asApa) (Figure 1, lane 3 vs. lane 4). Thus, when ORF2 or ORF2Apa was inserted in the antisense orientation most of the decrease in the expression of full-length GFP RNA was related to the generation of low molecular mass RNA species, indicating that antisense

Table 1 - Plasmids used in this study.

\begin{tabular}{|c|c|}
\hline Plasmids & Fragment inserted into pEGFP-C1 and annotation \\
\hline pORF2, pORF2as & $\begin{array}{l}\text { ORF2 inserted in sense or antisense (as) orientation downstream of GFP by us- } \\
\text { ing the restriction enzymes Xho I /Pst I. }\end{array}$ \\
\hline pORF2Apa, pORF2asApa & $\begin{array}{l}\text { ORF } 2 \text { inserted in sense or antisense orientation downstream of } G F P \text { by using } \\
\text { the restriction enzyme Apa I. }\end{array}$ \\
\hline pLacZ, pLacZas & $L a c Z$ inserted in sense or antisense orientation downstream of GFP. \\
\hline $\begin{array}{l}\text { p } 280-1 * 8, \text { p } 280-2 * 8, \text { p } 280-4 * 8, \text { p } 280-5 * 8, \text { p } 280-7 * 8, \text { p } 280-8 * 8 \\
\text { p } 280-9 * 8\end{array}$ & $\begin{array}{l}\text { Eight copies of fragments } 280-1,280-2,280-4,280-5,280-7,280-8 \text { and } 280-9 \\
\text { inserted in sense orientation downstream of GFP. }\end{array}$ \\
\hline pAlu*1, pAlu*2, pAlu*4, pAlu*8, pAlu*14 & $\begin{array}{l}\text { One, 2, } 4,8 \text { or } 14 \text { copies of } A l u \text { inserted in sense orientation downstream of } \\
\text { GFP. }\end{array}$ \\
\hline $\begin{array}{l}\text { p280-1*8as, p280-2*8as, p280-4*8as, p280-5*8as, p280-7*8as, } \\
\text { p280-8*8as, p280-9*8as }\end{array}$ & $\begin{array}{l}\text { Eight copies of fragments } 280-1,280-2,280-4,280-5,280-7,280-8,280-9 \text { in- } \\
\text { serted in antisense orientation downstream of GFP. }\end{array}$ \\
\hline pAlu*8as, pAlu*14as & Eight or 14 copies of $A l u$ inserted in antisense orientation downstream of $G F P$. \\
\hline p(AAACAAA)Rep, p(AAACAAA)Repas & $\begin{array}{l}\text { AAACAAA simple repeat ( } 736 \mathrm{bp} \text { ) inserted in sense or antisense orientation } \\
\text { downstream of GFP. }\end{array}$ \\
\hline p(AG)Rep, p(AG)Repas & $\begin{array}{l}\text { AG simple repeat ( } 736 \mathrm{bp} \text { ) inserted in sense or antisense orientation downstream } \\
\text { of GFP. }\end{array}$ \\
\hline p280-1 8as & $280-1 \sim 8$ fragment inserted in antisense orientation downstream of GFP. \\
\hline p $280-1 * 14, \mathrm{p} 280-1 * 14 \mathrm{as}$ & $\begin{array}{l}\text { Fourteen copies of fragment } 280-1 \text { inserted in sense or antisense orientation } \\
\text { downstream of GFP. }\end{array}$ \\
\hline p280-4*1,p280-4*2, p280-4*4, p280-4*14 & $\begin{array}{l}\text { One, } 2,4 \text {, or } 14 \text { copies of fragment } 280-4 \text { inserted in sense orientation down- } \\
\text { stream of } G F P \text {. }\end{array}$ \\
\hline
\end{tabular}


Table 2 - Primers and oligonucleotides used in this study.

\begin{tabular}{|c|c|c|}
\hline Amplified fragments & Restriction enzyme & Sequence of primers (The underlined sequences refer to the restriction sites) \\
\hline ORF2 (3825 bp) & Xho I / Pst I & $\begin{array}{l}\text { Forward: 5'-ATCGCTCGAGCTTAAATGACAGGATCAAA } \\
\text { TTCACAC-3'; } \\
\text { Reverse: 5'-ATCGCTGCAGTCAATTCCCACCTAT } \\
\text { TAGGG-3' }\end{array}$ \\
\hline ORF2as (3825 bp) & Pst I / Xho I & $\begin{array}{l}\text { Forward: 5'-ATCGCTCGAGCTTAATCAATTCCCACCTAT } \\
\text { TAGGG-3'; } \\
\text { Reverse: 5'-ATCGCTGCAGATGACAGGATCAAATT } \\
\text { CACAC-3' }\end{array}$ \\
\hline ORF2Apa (3825 bp) & Apa I & $\begin{array}{l}\text { Forward: 5'-ATCGGGGCCCCTTAAATGACAGGATCAA } \\
\text { ATTCACAC-3'; } \\
\text { Reverse: 5'-ATCGGGGCCCCTTAATCAATTCCCAC } \\
\text { CTATTAGGG-3' }\end{array}$ \\
\hline LacZ (3825 bp) & Xho I / Pst I & $\begin{array}{l}\text { Forward: 5'-ATCGCTCGAGCTTAATGACCATGATTACG } \\
\text { GATTCACTGG-3'; } \\
\text { Reverse: 5'-ATCGCTGCAGGGAAACGCCAATAAC } \\
\text { ATACAGTGAC-3' }\end{array}$ \\
\hline LacZas (3825 bp) & Xho I / Pst I & $\begin{array}{l}\text { Forward: 5'-ATCGCTCGAGCTTAGGAAACGCCAATAA } \\
\text { CATACAGTGAC-3'; } \\
\text { Reverse: 5'-ATCGCTGCAGATGACCATGATTACGG } \\
\text { ATTCACTGG-3' }\end{array}$ \\
\hline Alu (283 bp) & $\begin{array}{l}\text { EcoR I / Xba I } \\
\text { Kpn I / Nhe I }\end{array}$ & $\begin{array}{l}\text { Forward: 5'-ATCGGAATTCTTAATCTAGATAAGGCT } \\
\text { GGGCGCGGTGGCTCAC -3'; } \\
\text { Reverse:5'-ATCGGGTACCATGCTAGCTGAGACGGA GTCTCGCTGTG-3' }\end{array}$ \\
\hline $\begin{array}{l}280-1 \text { (The first } 280 \mathrm{bp} \text { of ORF2, } \\
\text { from } 1-280 \mathrm{bp} \text { ) }\end{array}$ & $\begin{array}{l}\text { EcoR I / Xba I } \\
\text { Kpn I / Nhe I }\end{array}$ & $\begin{array}{l}\text { Forward: 5'-ATCGGAATTCTTAATCTAGATAAATGA } \\
\text { CAGGATCAAATTCACA-3'; } \\
\text { Reverse: 5'-ATCGGGTACCATGCTAGCCTTTGTCTCTTT TGATCTTT-3 }\end{array}$ \\
\hline $\begin{array}{l}280-2 \text { (The second } 280 \mathrm{bp} \text { of ORF2, } \\
\text { from } 281-560 \mathrm{bp} \text { ) }\end{array}$ & $\begin{array}{l}\text { EcoR I / Xba I } \\
\text { Kpn I / Nhe I }\end{array}$ & $\begin{array}{l}\text { Forward: 5'-ATCGGAATTCTTAATCTAGATAAAAGG } \\
\text { CCATTACATAATGGT-3'; } \\
\text { Reverse: 5'-ATCGGGTACCATGCTAGCTTGGGGTGA AGAGTTCTGT-3' }\end{array}$ \\
\hline $\begin{array}{l}280-4 \text { (The fourth } 280 \mathrm{bp} \text { of ORF2, } \\
\text { from } 1006-1285 \mathrm{bp} \text { ) }\end{array}$ & $\begin{array}{l}\text { EcoR I / Xba I } \\
\text { Kpn I / Nhe I }\end{array}$ & $\begin{array}{l}\text { Forward: 5'-ATCGGAATTCTTAATCTAGATAAAGAA } \\
\text { GGCAAGAAATAACT-3'; } \\
\text { Reverse: 5'-ATCGGGTACCATGCTAGCTTTCTCCTA GATTTTCTAG-3' }\end{array}$ \\
\hline $\begin{array}{l}280-5 \text { (The fifth } 280 \text { bp of ORF2, } \\
\text { from } 1675-1954 \mathrm{bp} \text { ) }\end{array}$ & $\begin{array}{l}\text { EcoR I / Xba I } \\
\text { Kpn I / Nhe I }\end{array}$ & $\begin{array}{l}\text { Forward: 5'-ATCG } \underline{\text { GAATTCTTAATCTAGATAAATCC }} \\
\text { ACCATGATCAAGT-3'; } \\
\text { Reverse: 5'-ATCGGGTACCATGCTAGCGGGAATGCT TCCGTTTTT-3' }\end{array}$ \\
\hline $\begin{array}{l}280-7 \text { (The seventh } 280 \mathrm{bp} \text { of ORF2, } \\
\text { from } 2406-2685 \mathrm{bp} \text { ) }\end{array}$ & $\begin{array}{l}\text { EcoR I / Xba I } \\
\text { Kpn I / Nhe I }\end{array}$ & 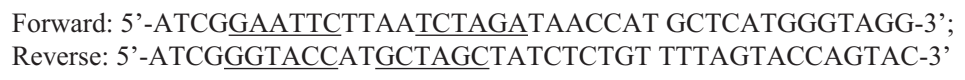 \\
\hline $\begin{array}{l}280-8 \text { (The eighth } 280 \mathrm{bp} \text { of ORF2, } \\
\text { from } 2933-3212 \mathrm{bp} \text { ) }\end{array}$ & $\begin{array}{l}\text { EcoR I / Xba I } \\
\text { Kpn I / Nhe I }\end{array}$ & $\begin{array}{l}\text { Forward: 5'-ATCGGAATTCTTAATCTAGATAAGGAA } \\
\text { AACCTAGGCATTAC-3'; } \\
\text { Reverse: 5'-ATCG } \underline{ } \text { 'ATACCATGCTAGCCCACTTTTT GATGGGGT-3' }\end{array}$ \\
\hline $\begin{array}{l}280-9 \text { (The ninth } 280 \text { bp of ORF2, } \\
\text { from } 3213-3492 \mathrm{bp} \text { ) }\end{array}$ & $\begin{array}{l}\text { EcoR I / Xba I } \\
\text { Kpn I / Nhe I }\end{array}$ & $\begin{array}{l}\text { Forward: 5'-ATCGGAATTCTTAATCTAGATAAGTGA AGGACATGAACAG-3'; } \\
\text { Reverse: 5'-ATCGGGTACCATGCTAGCTCCTAGATC CCTGAGGAAT-3' }\end{array}$ \\
\hline AAACAAA oligonucleotide (78 bp) & $\begin{array}{l}\text { EcoR I / Xba I/ } \\
\text { Nhe I / Kpn I }\end{array}$ & $\begin{array}{l}\text { Template: 5'-ATCGGAATTCTTAATCTAGAAAACAAA } \\
\text { AAACAAAAAACAAAAAACAAAAAACAAAAAACA } \\
\text { GCTAGCATGGTACCCGAT-3'; } \\
\text { Forward: 5'- ATCGGAATTCTTAATCTAGA-3'; } \\
\text { Reverse: 5'-ATCGGGTACCATGCTAGC-3' }\end{array}$ \\
\hline AG oligonucleotide (78 bp) & $\begin{array}{l}\text { EcoR I / Xba I/ } \\
\text { Nhe I / Kpn I }\end{array}$ & $\begin{array}{l}\text { 5' -ATCGGAATTCTTAATCTAGAAGAGAGAGAGAGA } \\
\text { GAGAGAGAGAGAGAGAGAGAGAGAGAGGCTAGC ATGGTACCCGAT-3' } \\
\text { Forward: 5'-ATCGGAATTCTTAATCTAGA-3'; } \\
\text { Reverse: 5'-ATCGGGTACCATGCTAGC-3' }\end{array}$ \\
\hline GFP probe (81 bp) & & $\begin{array}{l}\text { Forward: 5'-GGGCGAGGGCGATG-3'; } \\
\text { Reverse: 5' -GTGGGCCAGGGCAC-3' }\end{array}$ \\
\hline Neo probe (170 bp) & & $\begin{array}{l}\text { Forward: 5' -GCTCCTGCCGAGAAAGTATCC-3'; } \\
\text { Reverse: 5'- CCCTGATGCTCTTCGTCCAGAT-3' }\end{array}$ \\
\hline
\end{tabular}


ORF2 caused premature termination of GFP transcription. The insertion of lacZ in either orientation reduced RNA synthesis to low similar levels (Figure 1, lanes 5 and 6). The insertion of $l a c Z$ in antisense orientation caused premature termination of GFP transcription (Figure 1, lane 6), whereas the insertion of this gene in sense orientation induced transcriptional elongation (Figure 1, lane 5). These findings indicated that ORF2 in sense orientation caused much stronger gene inhibition than in antisense orientation, with the latter causing premature transcriptional termination.

\section{Effects of different 280-bp fragments of ORF2 on GFP expression}

To study the effects of ORF2 fragments on GFP expression, we obtained seven 280-bp fragments from different regions of ORF2, as shown in Figure 2C and Table 2. Head and tail, tandem 8 -sequence repeats (see Table 1) were constructed for each fragment. As shown in Figure 2, all of the inserts inhibited GFP transcription much more strongly in sense than in antisense orientation, which was consistent with the results for full-length ORF2 (Figure 1). Regardless of their orientation (sense or antisense), fragments 280-1 and 280-9 caused premature termination of transcription and produced low molecular mass RNA (Figure 2A, lanes 1 and 7; Figure 2B, lanes 1 and 7). Fragment 280-5 caused premature termination of GFP transcription

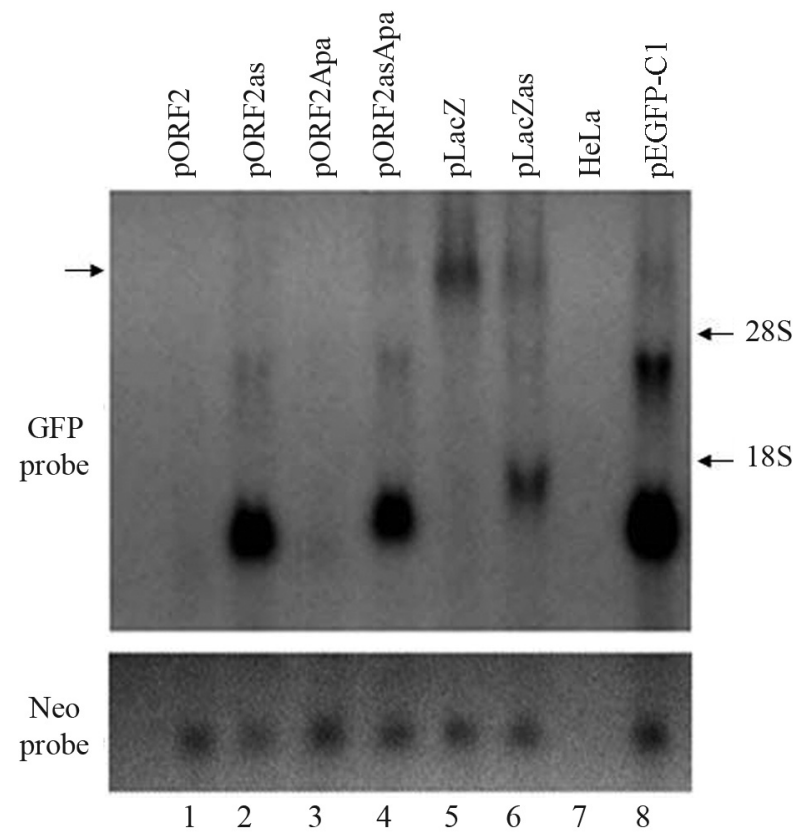

Figure 1 - Insertion of ORF2 in different orientations exerted distinct inhibitory effects on gene expression. Total RNA extracted from HeLa cells transfected with plasmids was analyzed by northern blotting. ORF2 in sense orientation inhibited GFP expression much more strongly than in antisense orientation; in the latter orientation ORF2 also caused premature transcriptional termination. Arrow on the left shows the expected positions of GFPORF2 and GFPlacZ that are of the same length. in sense orientation (Figure 2A, lane 4), whereas fragment 280-4 had the same effect in antisense orientation (Figure $2 \mathrm{~B}$, lane 3). Other ORF2 fragments, including fragments 280-2, 280-7 and 280-8, did not induce premature termination of GFP transcription in either orientation. Thus, in contrast to ORF2 which caused premature termination of GFP transcription when in antisense orientation, the effect of ORF2 fragments on transcriptional elongation were less predictable.

\section{Effects of simple repeats constructed from ORF2 fragments on GFP expression}

Since the different 280-bp ORF2 fragments had distinct effects on GFP expression in HeLa cells (Figure 2), we examined the influence of even shorter ORF fragments on gene expression. As shown in Table 3, the ORF2 fragments generally contained more A than T. We chose AAACAAA and AG, which are particularly abundant in ORF2, and constructed 736-bp repeats of these base sequences. The AAACAAA or AG repeats were then inserted into the pEGFP-C1 vector downstream of GFP in sense or antisense orientation. Fragments inserted in sense orientation suppressed transcription more strongly than those in antisense orientation (Figure 3), in agreement with the findings for ORF2 and its 280-bp fragments. Interestingly, AAACAAA repeats in either orientation caused premature transcriptional termination (Figure 3, lanes 1 and 2), whereas AG repeats in antisense orientation resulted in greater synthesis of higher molecular mass transcripts than did AG repeats in sense orientation (Figure 3, lane 4 vs. lane 3).

\section{ORF2 fragment 280-9 is responsible for premature transcriptional termination by ORF2 in antisense orientation}

As shown above (Figure 2), the ORF2 fragments had distinct effects on $G F P$ transcriptional elongation. Of seven 280-bp fragments, fragment 280-9 (the 3' end sequence of ORF2) caused premature transcriptional termination when inserted in antisense orientation (Figure 2B), in agreement with the results for ORF2 (Figure 1). These findings implied that when ORF2 is in antisense orientation the 3' end of ORF2 is responsible for premature transcriptional termination. To confirm this, the 3' end of ORF2, including fragment 280-9 and its downstream region, were deleted (the resulting fragment was referred to as $280-1 \sim 8$ ). When fragment 280-1 8 was inserted in the antisense orientation downstream of $G F P$ there was no premature transcriptional termination of this gene (Figure 4, lane 2), thus confirming the importance of the 3 ' end sequence of ORF2 in this phenomenon.

\section{ORF2 280-bp segments cause length-dependent reduction of RNA and protein expression}

We inserted 8 or 14 copies of ORF2 fragment 280-1 downstream of GFP in the pEGFP-C1 vector. With frag- 

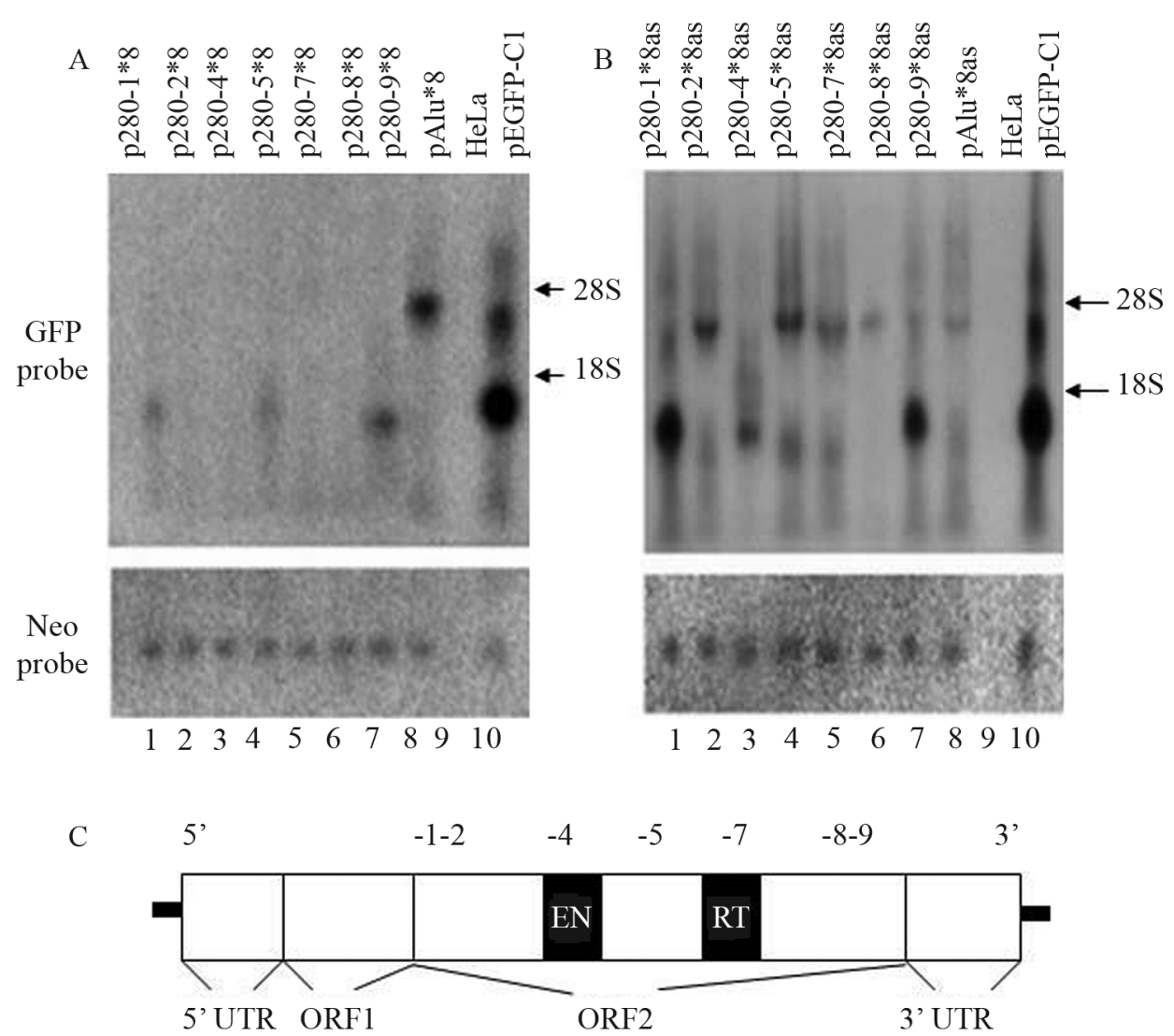

Figure 2 - Effects of 280-bp ORF2 fragments on GFP transcription. (A) The effects of seven 280-bp ORF2 fragments in sense orientation on gene transcription. Fragments 280-1, 280-5 and 280-9 fragments caused premature transcriptional termination and produced low molecular mass RNA (lanes 1, 4 and 7), whereas fragments 280-2, 280-7 and 280-8 did not cause premature termination of GFP transcription. (B) Effects on gene transcription of the same seven 280-bp ORF2 fragments in antisense orientation. Fragments 280-1, 280-4 and 280-9 caused premature transcriptional termination whereas other 280-bp fragments did not. (C) The basic structure of L1 and amplification sites of different 280-bp fragments. An intact L1 consists of 5' UTR, ORF1, ORF2 and 3'UTR. EN: endonuclease; RT: reverse transcriptase. -1 -9 indicates the sites of fragments obtained from ORF2. -1: 280-1 fragment, $-2: 280-2$ fragment, $-4: 280-4$ fragment, $-5: 280-5$ fragment, $-7: 280-7$ fragment, $-8: 280-8$ fragment and $-9: 280-9$ fragment.

ment 280-1 in either the sense or antisense orientation, the construct inhibited gene transcription in a length-dependent manner (Figure 5A, lane $4 v s$. lane 3; lane $8 v s$. lane 7). However, insertion of fragment 280-1 in sense orientation induced much stronger inhibition of GFP expression than did its insertion in antisense orientation, and when present in either orientation this fragment caused premature transcriptional termination.

Copies of ORF2 fragment 280-4 inserted in sense orientation downstream of GFP decreased RNA transcription
(Figure 5B) and protein expression (Figure 5C) in a length-dependent manner. The lengths of RNA transcripts increased with increasing numbers of copies of fragment 280-4 (Figure 5B, lanes 6-10), suggesting that fragment 280-4 did not cause premature termination of transcription.

$A l u$, used as a control in these experiments, also inhibited gene expression in a length-dependent manner but did not cause premature transcriptional termination (Figure 5A, lane $2 v s$. lane 1 and lane $6 v s$. lane 5; Figure 5B, lanes 1-5).

Table 3 - Base content of 280-bp ORF2 fragments.

\begin{tabular}{|c|c|c|c|c|c|c|c|}
\hline & \multicolumn{7}{|c|}{ Base number $\left(\%{ }^{1}\right)$ of ORF2 fragments } \\
\hline & $280-1$ & $280-2$ & $280-4$ & $280-5$ & $280-7$ & $280-8$ & $280-9$ \\
\hline A & $121(44)$ & 109 (39) & $136(49)$ & $114(41)$ & $107(38)$ & $126(45)$ & $106(38)$ \\
\hline $\mathrm{C}$ & 54 (19) & $67(24)$ & $51(18)$ & $58(21)$ & $63(23)$ & $60(21)$ & $54(19)$ \\
\hline G & $50(18)$ & $45(16)$ & $48(17)$ & $43(15)$ & $48(17)$ & $46(16)$ & $61(22)$ \\
\hline $\mathrm{T}$ & $55(20)$ & $59(21)$ & 45 (16) & $65(23)$ & $62(22)$ & $48(17)$ & $59(21)$ \\
\hline
\end{tabular}

${ }^{1}$ Percentage in each 280-bp fragment. 


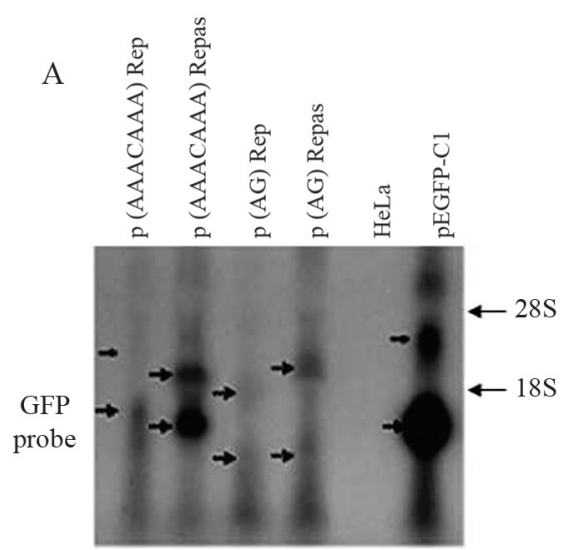

B
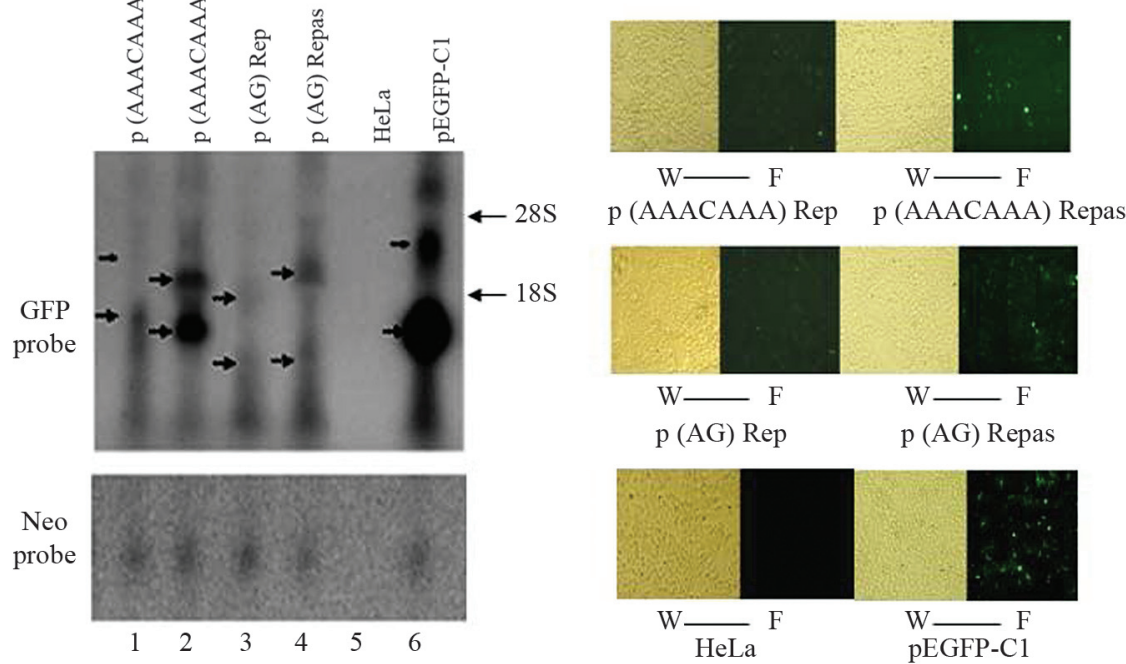

Figure 3 - Effects of simple repeats constructed from small A-rich ORF2 fragments on GFP gene expression. AAACAAA or AG 736-bp long repeats were inserted in sense or antisense orientation downstream of GFP. The inserts inhibited GFP transcription. AAACAAA repeats in either orientation induced premature transcriptional termination. AG repeats in antisense orientation produced a greater number of higher molecular mass transcripts than in sense orientation. Arrows indicate positions of low or high molecular mass transcripts.

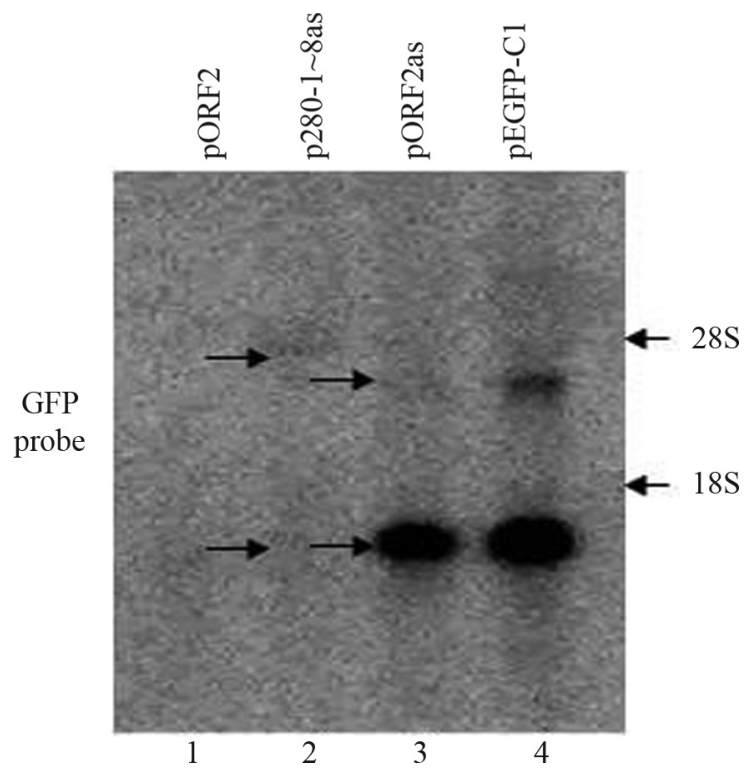

Figure 4 - The 280-1 8 fragment (generated by deleting 280-9 and its downstream region in ORF2) did not induce premature transcriptional termination when inserted in antisense orientation downstream of GFP (lane 2). Arrows show the positions of low or high molecular mass transcripts.

\section{Discussion}

L1 elements are associated with a number of biological phenomena including $\mathrm{X}$ chromosome inactivation (Bailey et al., 2000; Lyon, 2000), monoallelic gene expression (Allen et al., 2003), gene rearrangement (Burwinkel and Kilimann, 1998), tumorigenesis (Martin and Branciforte, 1993) and organic evolution (Deininger et al.,
2003; Hedges and Batzer, 2005). Most L1s in the human genome are truncated (Sassaman et al., 1997; Boissinot et al., 2000; Sheen et al., 2000) and L1 sequences found in introns are preferentially located in the antisense orientation (Smit, 1999; Medstrand et al., 2002). These characteristics provide an interesting situation for examining the influence of L1 fragments and their orientation on gene expression.

As shown here, the ORF2 of L1PA3 in sense orientation inhibited GFP expression much more than in antisense orientation, and caused premature transcriptional termination in the latter orientation, in agreement with previous findings for L1.2-ORF2 (Han et al., 2004). Although the sequences of L1.2-ORF2 and L1PA3-ORF2 are not identi$\mathrm{cal}$, they had similar effects on gene expression, suggesting that mutation of individual nucleotides does not affect the functions of this ORF.

Different restriction enzymes were used to construct plasmids with ORF2 in sense (pORF2 and pORF2Apa) and antisense (pORF2as and pORF2asApa) orientation. The insertion of ORF2 (Figure 1, lanes 1 and 2) or ORF2Apa (Figure 1, lanes 3 and 4) had the same effect on gene expression as when they were incorporated into plasmids in the same orientation, a finding that increased our confidence in the results of this study. The ORF2 sequence does not inhibit the initiation of transcription and is a poor substrate for transcriptional elongation (Han et al., 2004).

The influence of ORF2 fragments on transcriptional termination and gene inhibition was examined by using seven 280-bp ORF2 fragments lacking restriction enzyme sites that could otherwise disturb the base linkage within the fragments. Each fragment consisted of eight tandem re- 

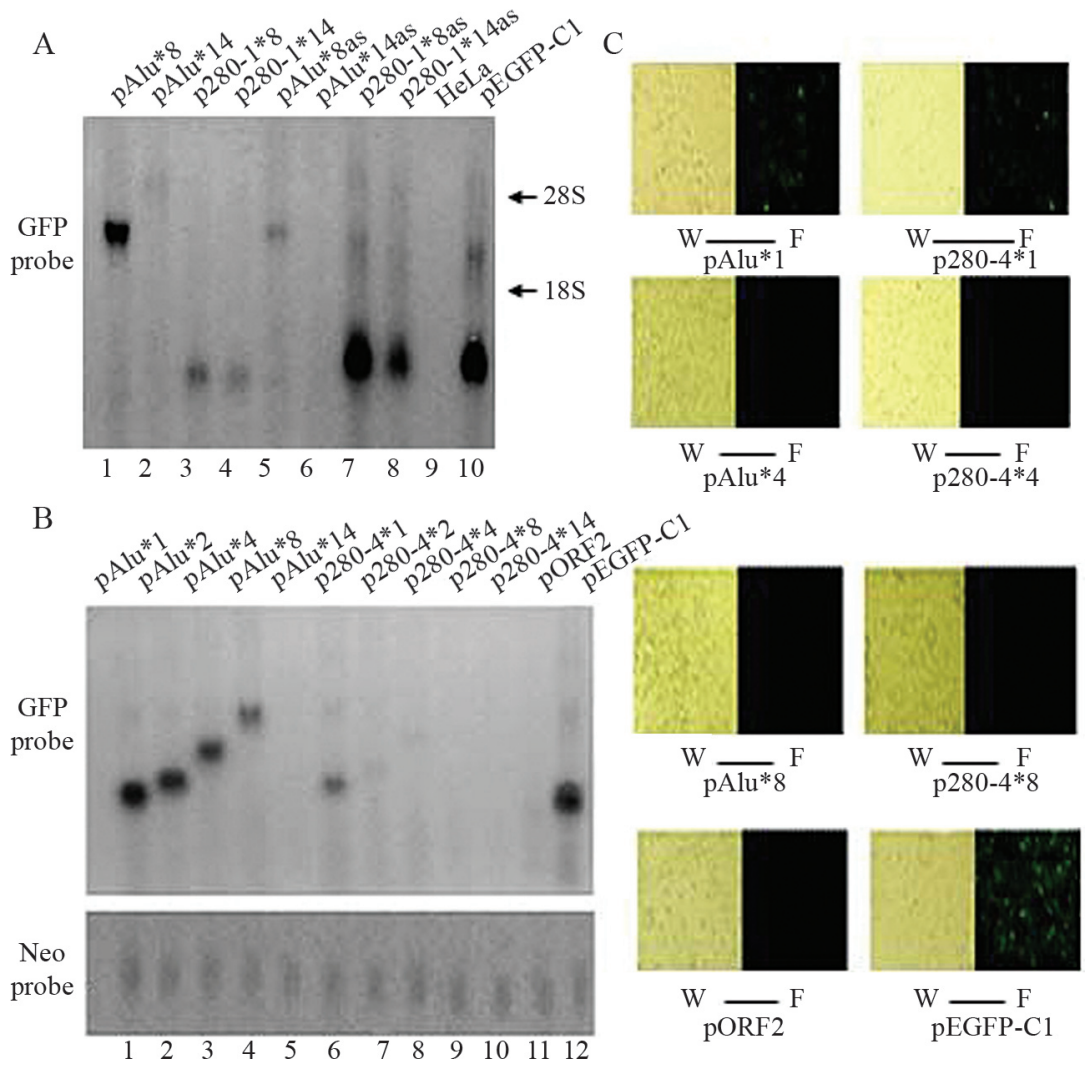

Figure 5 - Length-dependent inhibition of GFP transcription by fragment 280-1 inserted in either orientation (A) and fragment 280-4 in sense orientation (B), and of protein expression (C). Alu was used as a positive control in these experiments.

peats and was inserted downstream of GFP in sense or antisense orientation. All of the fragments significantly reduced gene expression, with greater inhibition when in sense compared to antisense orientation (Figure 2); this finding consistent with our observations for ORF2 (Figure 1).

Enhanced RNA degradation or decreased RNA production could reduce RNA concentrations. Han et al. (2004) stated that most of the decrease in GFP-ORF2 transcription in the presence of L1.2-ORF2 was not due to transcript degradation. In the present study, the bands seen in northern blots probably reflected the rate of gene transcription.

The 280-bp ORF2 fragments had different effects on transcriptional elongation. Fragments $280-1$ and 280-9 in sense or antisense orientation caused premature transcriptional termination (Figure 2A, lanes 1 and 7; Figure 2B, lanes 1 and 7). Fragment 280-5 in sense orientation (Figure 2A, lane 4) and fragment 280-4 in antisense orientation (Figure 2B, lane 3) also caused premature transcription termination. Other 280-bp fragments in either orientation did not cause premature transcription termination.

Mutations involving individual nucleotides did not affect ORF2 function, and each 280-bp fragment continued to have a stronger inhibitory effect in sense compared to antisense orientation. These findings prompted us to investigate the effects of fragments $<280 \mathrm{bp}$ on gene expression. L1 has an adenosine-rich (A-rich) bias in the sense strand (Deininger et al., 2003). We chose small fragments of AAACAAA and AG, which are abundant in ORF2. Fragments containing tandem repeats of AAACAAA and AG were used to ensure a sufficiently large effect on gene expression. As in the experiments with the 280-bp fragments, the AAACAAA and AG repeats showed much stronger inhibition in sense compared to antisense orientation. AAACAAA sequences were certified to be Sox 2 protein binding sites. The binding of Sox 2 protein to these sites suppresses gene expression driven by L1 5'-UTR (Muotri et al., 2005) and may be one of the mechanisms by which AAACAAA inhibits gene expression.

Figure 2 shows that the 280-bp ORF2 fragments had different effects on transcriptional termination. Fragment 280-9 in antisense orientation caused premature transcriptional termination (Figure 2B, lane 9) that resembled the results obtained with ORF2 in antisense orientation (Figure 1, lane 2). This finding suggested that fragment $280-9$ plays a key role in premature transcriptional termination by ORF 2 . To confirm this hypothesis, we deleted fragment 280-9 from the 3'end of ORF2 and inserted the resulting fragment (280-1 8) in antisense orientation downstream of GFP. This insert failed to stimulate the production of low molec- 
ular mass RNA similar to that seen with ORF2 in antisense orientation (see Figure 4). This result indicated that fragment 280-9 and its 3'end sequence play a key role in the premature transcriptional termination mediated by ORF2.

Since the chromosomal densities of Alu and L1 are negatively correlated with each another (except for the Y chromosome), and since L1 elements are responsible for the retrotransposition of Alu retroelements (Dewannieux et al., 2003), Alu was used as a parallel control in some experiments. The genomic distribution of Alu is suggestive of a possible involvement in enhancing gene expression. However, as shown here, Alu inhibited gene expression in a length-dependent manner (Figure 5), but had a much weaker effect than ORF2 fragments 280-1 or 280-4. In addition, Alu did not cause premature transcriptional termination. ORF2 may cause premature transcriptional termination (Figure 1, lanes 1-4; Figure 4, lanes 1 and 3) through the presence of multiple functional canonical and noncanonical polyA signals in L1 (Deininger et al., 2003). Such signals are also present in some ORF2 fragments, e.g., fragments $280-9$ and 280-1, where they presumably also promote termination. Han et al. (2004) found that tandem L1.2-ORF1 caused length-dependent inhibited of gene expression. As shown here, 280-1, 280-4 and Alu in either orientation also caused length-dependent suppression of gene expression.

In conclusion, we have described a number of potentially important functions of ORF2 and its fragments that affect gene expression. The major findings of this work are that: (1) ORF2 fragments contributed differently to gene transcriptional elongation, with only some fragments inducing the premature transcriptional termination seen with ORF2, (2) in deletion studies, the 3' end sequence of ORF2 (fragment 280-9) is responsible for the premature transcriptional termination observed with ORF2 in antisense orientation, and (3) all of the ORF2 fragments studied here, as well as ORF2 itself, inhibited gene expression much more in sense compared to antisense orientation. The latter observation suggested that small fragments contributed to ORF2-mediated inhibition of gene expression primarily when in sense orientation.

\section{Acknowledgments}

This study was supported by grant C2008001065 from the Hebei Province Natural Science Foundation of China.

\section{References}

Abrusán G, Krambeck HJ, Junier T, Giordano J and Warburton PE (2008) Biased distributions and decay of long interspersed nuclear elements in the chicken genome. Genetics 178:573-581.

Allen E, Horvath S and Tong F (2003) High concentrations of long interspersed nuclear element sequence distinguish monoallelically expressed genes. Proc Natl Acad Sci USA 100:9940-9945.
Athanikar JN, Badge RM and Moran JV (2004) A YY1-binding site is required for accurate human LINE-1 transcription initiation. Nucleic Acids Res 32:3846-3855.

Bailey JA, Carrel L and Chakravarti A (2000) Molecular evidence for a relationship between LINE-1 elements and X chromosome inactivation: The Lyon repeat hypothesis. Proc Natl Acad Sci USA 97:6634-6639.

Belancio VP, Hedges DJ and Deininger P (2006) LINE-1 RNA splicing and influences on mammalian gene expression. Nucleic Acids Res 34:1512-1521.

Boissinot S, Chevret P and Furano AV (2000) L1 (LINE-1) retrotransposon evolution and amplification in recent human history. Mol Biol Evol 17:915-928.

Burwinkel B and Kilimann MW (1998) Unequal homologous recombination between LINE-1 elements as a mutational mechanism in human genetic disease. J Mol Biol 277:513-517.

Cost GJ, Feng Q, Jacquier A and Boeke J (2002) Human L1 element target-primed reverse transcription in vitro. EMBO J 21:5899-5910.

Deininger PL, Moran JV, Batzer MA and Kazazian Jr HH (2003) Mobile elements and mammalian genome evolution. Curr Opin Genet Dev 13:651-658.

Dewannieux M, Esnault C and Heidmann T (2003) LINEmediated retrotransposition of marked Alu sequences. Nat Genet 35:41-48.

Ergün S, Buschmann C, Heukeshoven J, Dammann K, Schnieders F, Lauke H, Chalajour F, Kilic N, Strätling WH and Schumann GG (2004) Cell type-specific expression of LINE-1 open reading frames 1 and 2 in fetal and adult human tissues. J Biol Chem 279:27753-27763.

Feng Q, Moran JV, Kazazian Jr HH and Boeke JD (1996) Human L1 retrotransposon encodes a conserved endonuclease required for retrotransposition. Cell 87:905-916.

Graham T and Boissinot S (2006) The genomic distribution of L1 elements: The role of insertion bias and natural selection. J Biomed Biotechnol 2006:75327-75331.

Hackenberg M, Bernaola-Galvan P, Carpena P and Oliver JL (2005) The biased distribution of alus in human isochores might be driven by recombination. J Mol Evol 60:365-377.

Han JS, Szak ST and Boeke JD (2004) Transcriptional disruption by the L1 retrotransposon and implications for mammalian transcriptomes. Nature 429:268-274.

Hedges DJ and Batzer MA (2005) From the margins of the genome: Mobile elements shape primate evolution. Bioessays 27:785-794.

Kazazian Jr HH and Moran JV (1998) The impact of L1 retrotransposons on the human genome. Nat Genet19:19-24.

Lander ES, Linton LM, Birren B, Nusbaum C, Zody MC, Baldwin J, Devon K, Dewar K, Dovle M, FitzHugh W, et al (2001) Initial sequencing and analysis of the human genome. Nature 409:860-921.

Lyon MF (2000) LINE-1 elements and X chromosome inactivation: A function for "junk" DNA? Proc Natl Acad Sci USA 97:6248-6249.

Martin SL and Branciforte D (1993) Synchronous expression of LINE-1 RNA and protein in mouse embryonal carcinoma cells. Mol Cell Biol 13:5383-5392.

Martin SL and Bushman FD (2001) Nucleic acid chaperone activity of the ORF1 protein from the mouse LINE-1 retrotransposon. Mol Cell Biol 21:467-475. 
Martin SL, Cruceanu M, Branciforte D, Wai-Lun Li P, Kwok SC, Hodges RS and Williams MC (2005) LINE-1 retrotransposition requires the nucleic acid chaperone activity of the ORF1 protein. J Mol Biol 348:549-561.

Medstrand P, van de Lagemeat LN and Mager DL (2002) Retroelement distributions in the human genome: Variations associated with age and proximity to genes. Genome Res 12:1483-1495.

Moran JV, Holmes SE, Naas TP, DeBerardinis RJ, Boeke JD and Kazazian Jr HH (1996) High frequency retrotransposition in cultured mammalian cells. Cell 87:917-927.

Muotri A, Chu VT, Marchetto MCN, Deng W, Moran JV and Gage FH (2005) Somatic mosaicism in neuronal precursor cells mediated by L1 retrotransposition. Nature 435:903910 .

Okano K, Zhang Q, Kimura S, Nartta J, Tanaka T, Fukuda H and Kondo A (2008) System using tandem repeats of the cA peptidoglycan-binding domain from Lactococcus lactis for display of both $\mathrm{N}$ - and C-terminal fusions on cell surfaces of lactic acid bacteria. Appl Environ Microbiol 74:1117-1123.

Pavlicek A, Jabbari K, Paces J, Paces V, Hejnar J and Bernardi G (2001) Similar integration but different stability of Alus and LINEs in the human genome. Gene 276:39-45.

Sassaman DM, Dombroski BA, Moran JV, Kimberland ML, Naas TP, DeBerardinis RJ, Gabriel A, Swergold GD and Kazazian Jr HH (1997) Many human L1 elements are capable of retrotransposition. Nat Genet 16:6-7.
Sciamanna I, Landriscina M, Pittoggi C, Quirino M, Mearelli C, Beraldi R, Mattei E, Serafino A, Cassano A, SinibaldiVallebona P, et al. (2005) Inhibition of endogenous reverse transcriptase antagonizes human tumor growth. Oncogene 24:3923-3931.

Sheen FM, Sherry ST, Risch GM, Robichaux M, Nasidze I, Stoneking M, Batzer MA and Swerqold GD (2000) Reading between the LINEs: Human genomic variation induced by LINE-1 retrotransposition. Genome Res 10:1496-1508.

Skowronski J and Singer MF (1986) The abundant LINE-1 family of repeated DNA sequences in mammals: Genes and pseudogenes. Cold Spring Harb Symp Quant Biol 51:457-464.

Smit AF (1999) Interspersed repeats and other mementos of transposable elements in mammalian genomes. Curr Opin Genet Dev 9:657-663.

Swergold GD (1990) Identification, characterization, and cell specificity of a human LINE-1 promoter. Mol Cell Biol 10:6718-6729.

Weichenrieder O, Repanas K and Perrakis A (2004) Crystal structure of the targeting endonuclease of the human LINE-1 retrotransposon. Structure 12:975-986.

Yang S, Smit AF, Schwartz S, Chiaromonte F, Roskin KM, Haussler D, Miller W and Hardison RC (2004) Patterns of insertions and their covariation with substitutions in the rat, mouse, and human genomes. Genome Res 14:517-527.

Associate Editor: Carlos F.M. Menck

License information: This is an open-access article distributed under the terms of the Creative Commons Attribution License, which permits unrestricted use, distribution, and reproduction in any medium, provided the original work is properly cited. 